\title{
Cryptocurrencies in the Global Financial System: Problems and Ways to Overcome them
}

\author{
Luchkin A.G.* \\ Department of Management and Customs \\ REU them. G.V. Plekhanova, Smolensk branch \\ Smolensk, Russia \\ e-mail: region-67@mail.ru
}

\author{
Novikova N.E. \\ Department of Economics and Trade \\ REU them. G.V. Plekhanova, Smolensk branch \\ Smolensk, Russia \\ e-mail: novikovane2013@yandex.ru \\ Zyatkova A.V. \\ Department of Management and Customs \\ REU them. G.V. Plekhanova, Smolensk branch \\ Smolensk, Russia \\ e-mail: zyatkova2012@yandex.ru
}

\author{
Lukasheva O.L. \\ Department of Economics and Trade \\ REU them. G.V. Plekhanova, Smolensk branch \\ Smolensk, Russia \\ e-mail: zharova-olga-21@yandex.ru
}

\author{
Melnikov V.A. \\ Department of Management and Customs \\ REU them. G.V. Plekhanova, Smolensk branch \\ Smolensk, Russiae-mail: melnikov.va@ rea.ru
}

\begin{abstract}
The subject of the study is cryptocurrencies from the perspective of the possibility of using them as a means of payment in the context of economy digitalization. The aim of the work is to assess the possible consequences of the further spread of cryptocurrency in the global financial system and to find ways to overcome them. The article analyzes the history of the emergence and development of money circulation systems from the gold standard to modern conditions for the emergence of cryptocurrencies, and also discusses the possibilities of using cryptocurrencies in fraudulent schemes. As a result of the study, the following tasks were solved: a historical analysis of money circulation systems was carried out; modern trends in the development of modern payment systems were revealed; the possibilities of using electronic and virtual money in modern conditions of digital economy development were analyzed; digital fraud opportunities were evaluated; the ways of regulating cryptographic money turnover were revealed. A historical analysis of monetary systems development enables to identify the objective reasons for the emergence of cryptocurrencies and the need to develop a legal and economic mechanism for their regulation in the digital economy development. Description of cryptocurrency fraud schemes enables to identify possible ways to stop them. The problem of organizational development of the settlement of relations in the field of cryptocurrency exchange, which will prepare the Russian financial system, reduce potential risks and learn how to use the benefits arising from the cryptocurrency turnover, is being solved.
\end{abstract}

Keywords - money system, digital economy, cryptocurrency, mining, digital money, cryptography

\section{INTRODUCTION}

The digital economy age contributes to the rapid development of the global financial system. This leads both to new opportunities for society and new threats. Computer technology evolution has led to the emergence of a new financial instrument, namely cryptographic money or cryptocurrencies. Despite the fact that they originated quite recently, the topic of virtual money is interesting for many people. Moreover, there are different perspectives regarding their impact on the economy. Some people are positive about it as digital technologies are largely accepted in modern life. Others, on the contrary, are opposed to the use of cryptocurrencies and believe that virtual money affects the historically established economic and financial relations in the world rather negatively.

Most of the population ignores the fact of cryptographic money existence. However, despite the still limited use of digital money, it is impossible to deny it. Even today, individual countries recognize cryptocurrency as a means of payment. It becomes possible to withdraw it to bank and electronic payment system accounts.

Modern society is quite ready to use virtual money but is the state ready for this? In digital economy it is rather difficult to ensure national and, particularly financial, security. Cryptocurrency today falls into the list of possible threats to the economy. This is due to its insufficient study from legal and economic points of view, lack of an established legal regulatory framework and incompletely disclosed potential of its use.

The purpose of the study is to assess the possible consequences concerning the further spread of cryptocurrency in the global financial system and to find ways to overcome them. Obviously, understanding its nature and potential areas 
of its use is necessary for determining the boundaries of application and establishing control over digital money circulation. A clear understanding of the fundamental differences between fiduciary and virtual money is necessary for assessing and consolidating the legal status of cryptocurrency as well as for developing an effective mechanism for state control over its circulation.

The research methods were the analysis, systematization and generalization of information contained in literature, documentary and Internet sources related to cryptographic money.

\section{LITERATURE REVIEW}

Monetary system is an integral part of any state associated with the organization of monetary circulation. It historically evolves in a separate state and is fixed by relevant legislation. Elements the monetary system consists of are as follows:

- monetary unit is a monetary symbol fixed by law which reflects the value of goods and services;

- the prices scale is manifested in terms of goods value in monetary units of the state;

- types of money;

- emission system is a procedure for the issue and circulation of banknotes in accordance with the law;

- regulation of monetary circulation.

Basing on the prevailing elements of a monetary system, the following types of monetary systems are distinguished:

- metal circulation systems in which it is necessary to distinguish two subspecies: bimetallic and monometallic systems;

- money circulation systems in which monetary notes and credit money not exchanged for gold and silver are used in circulation.

One of the first monetary systems was a silver standard. This system of the $16^{\text {th }}-19^{\text {th }}$ centuries was based on silver. In the period of the silver standard various countries preferred to use not only silver but also gold. This type of monetary system was called bimetallic. It is characterized by the fact that the function of the universal equivalent is performed by two types of metal (gold and silver). In the history of the development and formation of monetary systems, the following three types of bimetallism have formed:

- a parallel currency system that fixes the ratio between metals depending on the price level in the market;

- a double currency system, which implies recording the ratio between the two metals at the legislative level;

- a system of lame currency characterized by the presence of the rights of private individuals to make coins from gold or silver bars they have at the mint, while there are clearly established relations between gold and silver coins.
Further development of the monetary system was found in monometallism, which implies one monetary metal functioning. In international practice, gold monometallism in which there are the following three types of standard is most common:

- gold coin;

- gold bullion;

- gold exchange

Gold-coin monometallism functioned in the countries characterized by the use of coins made of gold in money circulation, and it operated until the First World War. This standard is characterized by a number of features from which the following ones should be highlighted:

- the price of each product is determined in gold;

- gold coins operate in the domestic market;

- gold has all the functions of money;

- gold coins can be freely minted;

- banknotes are exchanged free of charge for gold;

- import and export of gold to the domestic market is carried out in a free mode;

- the presence of free gold markets.

During the First World War, many countries were forced to use part of their gold and foreign exchange reserves, the level of which decreased significantly by the end of the war, and this led to the emergence of a gold bullion standard. This standard enables to exchange banknotes and other types of money for gold bars weighing $12.5 \mathrm{~kg}$.

The main feature of the gold currency (gold exchange) standard is the opportunity to exchange banknotes and other money for the currency of the mottos of countries where gold exchange is allowed. After 1929-1933, all forms of gold monometallism were eliminated.

The middle of the 30 s of the $20^{\text {th }}$ century was marked by generating the monetary systems based on the circulation of non-changeable credit signs in the world practice.

The main characteristics of monetary systems based on the circulation of non-refundable credit signs are as follows:

- gold is used only to store state reserves, that is, gold serves as a treasure;

- gold is not used in exchange operations on the domestic and foreign markets;

- banknotes are issued on the basis of bank credit operations;

- the prevalence of non-cash money and a decrease in cash turnover.

The next historical stage in the development of monetary systems was the conference in Bretton Woods (USA), which took place in 1944 and became the starting point for the creation of the Bretton Woods monetary system as well as the 
beginning of the International Monetary Fund and the International Bank for Reconstruction and Development.

For the Bretton Woods system as well as for other monetary systems, the following features are adherent:

- gold is used only for final settlements between countries and is not involved in free circulation;

- inclusion in the international settlement system as well as in the reserve currency of the US dollar and pound sterling (Great Britain);

- gold is exchanged only for reserve currencies in accordance with the agreed ratio or in free gold markets;

- interstate settlement of foreign exchange relations is carried out through the International Monetary Fund.

During the existence of the Bretton Woods monetary system, the US dollar played the role of a reserve currency that could be exchanged for gold, which led to the emergence of the dollar standard. It was caused by the fact that in the middle of the 20th century $70 \%$ of the world's gold reserves were concentrated in the USA. But in the 70 s of the $20^{\text {th }}$ century, there was a decrease in gold reserves in the United States, which led to the need to replace the Bretton Woods monetary system.

The transformation of the Bretton Woods monetary system led to the emergence of the Jamaican monetary system, which is characterized by free currency conversion. It was drawn up in 1976 by the Agreement of the IMF member countries (Jamaica) and approved by the same countries in 1978 .

The Jamaican monetary system is characterized by the following distinctive features:

- the international monetary unit is a set of special drawing rights (SDR), which play the role of world money;

- gold has lost its function of money;

- the gold reserve and gold parities were canceled;

- the dollar has recovered a leading role in international payments and in the formation of reserves;

- the exchange rate is set as freely floating.

In modern conditions, the Jamaican monetary system remains the main in the system of international monetary relations. But this system is characterized by individual contradictions, for example, the imperfection of floating rates as well as the priority position of individual developed states.

Currently in most countries the main type of banknotes are credit bank notes (banknotes), state money (treasury tickets) and a small coin A close relationship has been established between money circulation and credit relations, and non-cash payment is also widely used [3, 6, 7].

Also, one cannot fail to note the role of technological and software innovations of recent years, thanks to which it became possible to develop our own models of payment systems. As an example, cryptocurrency is a kind of digital currency, the creation and control of which is based on cryptographic methods. Functioning of these systems is based on technologies such as blockchain, directional acyclic graph, consensus register (ledger), etc. Information about ongoing cash transactions, as a rule, is not encrypted and is publicly available. In order to ensure the invariability of the base of the transaction blocks chain, cryptography elements are used, which are a digital signature based on a public key system.

One of the first experiences of cryptography usage was a centralized system of confidential payments organized by David Chaum's DigiCash. Unfortunately, this company went bankrupt in 1998 .

In 2009, the Bitcoin payment system was developed by a person or a group of people under the pseudonym SatoshiNakamoto, which generated the term "cryptocurrency". The following forks later appeared: Namecoin, Litecoin, PPCoin, Novacoin and many others.

Until July 2013, all cryptocurrency software, with the exception of Ripple, was based on the open source Bitcoin system. Later, new platforms accepting not only cryptocurrencies but also various infrastructures such as exchange transactions, shops, instant messengers, etc. began to appear. Such cryptographic platforms include BitShares, Mastercoin, Nxt. In addition, other platforms are being announced.

The emergence of cryptocurrencies is the first step in bringing the current monetary system to a new digital level of development.

In modern conditions of expanding the scope of digital technologies, one of the directions of cryptocurrency circulation development is the use of "virtual currencies" when purchasing certain types of goods and services.

In modern world practice, there are about 500 types of cryptocurrencies, although Bitcoin and Litecoin are the leaders in this list.

A special feature of these cryptocurrencies is that they are accepted by all existing exchanges and exchange points. The cryptocurrencies that have been arising lately are the derivatives of Bitcoin as they are built on the basis of its open source code, which, accordingly, leads to their lesser popularity.

In the 1980s, when the first theories justifying the possibility of electronic and virtual money and currencies appeared, they seemed fantastic. However, in 1993 the central banks of the European Union conducted a study on the possibility of using electronic or "network" money. The study of central banks was primarily aimed at the possibility of their use in the prepaid payment system. In 1994 the central banks of Europe recognized the existence of "electronic money" and noted the advantages that they had. Specifically, these are low cost and a high level of technical security. At a meeting of central banks G10 representatives in 1996, it was decided to create a system for accounting and monitoring electronic money, although an accounting system for them was developed only by the year 2000 . 
There is still no consensus among developed countries regarding the terminology of electronic money. However, the basis of this concept is formed by a monetary obligation in electronic form. In this regard, debt receipts required at the legislative level create the basis for a new type of money $[1,2,5]$.

In 2008, a new term "cryptocurrencies" appeared. This was caused by the publication under the name SatoshiNakamoto of a document that justifies the Bitcoin system. It is still unknown whether one author or a group is hiding under this pseudonym.

In January, 2009 the bitcoin network began its work with the release of the first bitcoin client and the creation of the first block, for which a reward of 50 bitcoins was received. From this period, the release and distribution of a new currency began. At that time it was quite small, and network participants actively carried out its production (this process was called mining). The first miners set the task of creating a certain number of coins, while it was possible to use personal computers. However, the increase in the number of created coins led to a more complicated form of their obtaining. At present significant computer resources are required to obtain them. Since a large number of people had no idea about the appearance of a new payment instrument, the degree of demand for cryptocurrencies was almost zero. In 2009, 700-1600 bitcoins were equal to one US dollar, and the cost was calculated based on the ratio of the product of the average electricity power and the power consumed by the device to the total number of bitcoins obtained.

Bitcoins first appeared as a payment tool in 2010, when one user of the system purchased two pizzas from another at a price of 10,000 bitcoins (approximately 25 US dollars). However, this course, soon, has undergone major changes. A couple of months after the publication about a new payment system on the Slashdot website, the rate grew by about 10 times. In 2011, the exchange MtGox aimed to exchange bitcoins with real money and vice versa was launched. The author of this exchange was JedMakKaleb.

The growing popularity of bitcoin causes certain difficulties, for example, in recent years, significant jumps in these currencies have been observed despite the fact that they are not provided with anything. In this regard, hackers also began to show great interest in obtaining cryptocurrency. Since all actions with cryptocurrencies took place on the basis of complete anonymity it was not difficult for them to seize the Bitcoin currency fraudulently. The following situation occurred in June 2011: an unknown hacker logged into the MtGox system using the account of one of its system administrators, and through a series of actions he acquired 2000 bitcoins at a low price. The system administrators admitted that they were not ready for such a situation, therefore they were forced to suspend the operation of the exchange for a week, and all operations completed at that time were invalidated $[4,8,9]$.

In process of time, the popularity of the bitcoin exchange rate continued to grow. Thus, by the end of February 2013, the rate of this cryptocurrency reached $\$ 31$. By April of that year, the exchange rate had tripled and reached $\$ 100$. The growth continued and within a month the exchange rate reached $\$ 266$, but then there was a sharp decline to $\$ 65$. These events were constantly covered by the media. Ultimately, by the end of 2013, the Bitcoin exchange rate exceeded $\$ 300$.

However, in 2013, the reputation of the bitcoin system was significantly affected. Bitcoins favoured the online-trading of drugs and other illegal goods and services. This trade was carried out by the owner of the "black market" SilkRoad through the anonymous network Tor. After this situation and a number of other events, governments developed different positions in relation to the bitcoin system. In China, the Central Bank has banned state-owned companies and financial institutions to use bitcoin for various operations. In Europe, they tried to warn and inform users that as a result of a sharp drop in the rate of bitcoin, it will be impossible to receive any compensation.

In the summer, 2015, at a conference of young IT specialists Russian President Vladimir Putin noted that the use of cryptocurrencies was permissible as a form of payment in certain areas. Vladimir Putin and Elvira Nabiullina, the head of the Bank of Russia, actively discussed the problems and prospects of using digital currencies as part of the digital economy development. In their opinion, there are a number of fundamental obstacles to their use.

In 2016, a positive news background began to form around the first cryptocurrency. The number of Bitcoin ATMs increased to 771. In Switzerland it became possible to purchase tickets for BTC coins. Other cryptocurrencies, in particular, Monero cryptocurrency gained popularity. All this influenced the growth of the Bitcoin exchange rate.

In December 2017, a crypto boom during which Bitcoin reached a record rate of $\$ 19,346$ occurred. This was due to the high popularity of this cryptocurrency as well as the news that American exchanges are to allow the trading of bitcoin futures from 2018.

However, in early 2018, after a number of reasons (problems with Google, the Chinese government called for pressure on miners due to high energy consumption), the bitcoin exchange rate fell to $\$ 7,000$. Gradually, it stabilized a little but in May the tension among traders and a drop in trading volumes caused the decline in the digital asset.

The history of cryptocurrencies shows that their popularity continues to grow. There are the machines for paying for a product using BTC coins appearing. It is possible that over time cryptocurrencies will be widely used without the use of special equipment and complex accounts. If the technology development simplifies the process of using cryptocurrencies, virtual money will turn into an ordinary payment instrument.

\section{DISCUSSION}

Currently, cryptocurrencies have gained a great popularity, which has led to the emergence of different types of digital currencies. One of the most famous cryptocurrencies is Bitcoin. At the moment, its cost is 6459.23 dollars. It reached its maximum value in December, 2017 and amounted to $\$ 20,000$, which entailed great excitement and public interest. 
The field of cryptocurrencies is open and decentralized, so the protection mechanism is limited. Thus, digital money as well as paper money can be attacked by scammers. Let us consider the possible types of fraud.

The first is Fake Wallets. Nowadays, everyone has online wallets designed to store money and carry out various operations. Cryptocurrencies are not an exception.

Secondly, there are four types of digital money wallets, such as:

- hardware wallets;

- web wallets;

- desktop wallets;

- mobile wallets.

This type of fraud involves creating fake applications for storing cryptocurrencies. For example, such fakes for Bitcoin usually have a name and logo similar to official wallets (Coinbase and Mycelium). Adventurers confuse inexperienced cryptocurrency owners who think they are installing the official app that appears in the recommendations.

Another way to attract customers to fake wallets is to promise transaction anonymity.

The fraud scheme is as follows:

1. An owner sets a wallet.

2. He uses it.

3. When a certain threshold is reached, the amount is withdrawn from the wallet.

The way to deal with this type of fraud is simple: you should download wallets only from official sources.

The next is cloud mining fraud. It implies that companies of this type of activity charge commissions from users in exchange for capacity for mining cryptocurrencies on behalf of the user. This process provides income for the extraction of cryptocurrencies by people without the acquisition and maintenance of expensive equipment.

This sphere is filled with swindlers. Fake mining is a website that offers the opportunity to acquire facilities but actually there will be no mining. Similar sites pay users for a certain time after the contract signing. Further, after a while, the company does not pay anything, and also the funds of users disappear.

Cloud mining fraud is, roughly speaking, a financial pyramid, because this activity is carried out while new users are attracted to the company.

In order to avoid cheating in cloud mining, you should carefully analyze the companies that provide these services. The main thing is not to forget that comments and reviews are not a guarantee of the good work of cloud mining, as it can be part of guerrilla marketing as well as people involved in the work of this pyramid.
Investment schemes are another type of fraud. These schemes are similar to cloud mining as they also promise profitability and make small payments every day until all payments are stopped at one point and a scammer disappears with the funds.

Such investments initially seem profitable, and users restart investing in anticipation of large profits. However, when users try to withdraw the income, problems appear and they lose their money.

In order not to fall for the bait, you need to make sure that the company is owned by professionals and that the strategies as well as all kinds of risks and solutions are fully described. In the world of investments, there is never one hundred percent confidence in profitability, so you should always be on the lookout.

Cryptocurrency network marketing is another type of pyramid. Here, the funds paid to the participants are not the company income but become the money of new investors. This scheme is not different from the pyramids in fiat, but most people get hooked due to new variables because there is an illusion that with the participation of cryptocurrency there will be something fundamentally different.

The next type of fraud is fake exchanges and exchangers. Cryptocurrency exchangers allow one coin to be exchanged for another, to deposit or withdraw fiat money (money unsecured by gold or other precious metal).

The digital money exchange provides the opportunity to speculate in currencies and buy cryptocurrencies at a better price, which is set during the auction. Such exchanges ask you to make a payment, which then goes to buy digital currency, but nothing is transferred back. These companies attract customers due to the reduced commission, the acceptance of a large number of means of payment, etc.

In order to avoid fraud, you should use only trusted exchanges and exchangers. However, sometimes even they are not protected from collapse. New resources should be checked with a small amount of cash.

Another fraud type is phishing with bitcoins. It implies sending emails in order to steal the personal information of users. The victim receives a letter saying that she won bitcoins. To collect money you need to enter your wallet.

A user usually provides fraudsters with data and loses access to the wallet. In this case, you need to be careful with various links, if the link seems suspicious, then it is better to ignore it.

Fraud speculation on the cryptocurrency market is one more type of fraud. Regulators in the financial markets are justified. One of their functions is to prevent speculators from outbidding and creating panic. Such regulation should soon appear on the cryptocurrency market, otherwise the situation will continue when investors with a large number of cryptocurrencies force traders with less currency to open or close trading positions.

Investors behave cautiously and prices do not change much without the participation of large speculators. However, with 
the release of a large number of currencies or artificial understatement and price increases, cryptocurrency rates change dramatically. In this case, many investors lose money due to panic, while others profit from inexperienced traders.

In this type of fraud, scams such as fake walls for sale or purchase are popular (figure 1). If a trader's strategy is not based on the analysis of cryptocurrency charts, then there's nothing to be afraid of. However, most traders watch every movement of cryptocurrencies on the chart and can be deceived by the so-called "walls" of buying or selling. Such "walls" sometimes appear due to real market fluctuations. On the chart of buy or sell orders, you can sometimes see a large wall on the right or left. This means that many traders are engaged in buying or selling cryptocurrency as a result of the sudden appearance or shortage of a large number of coins in the market.

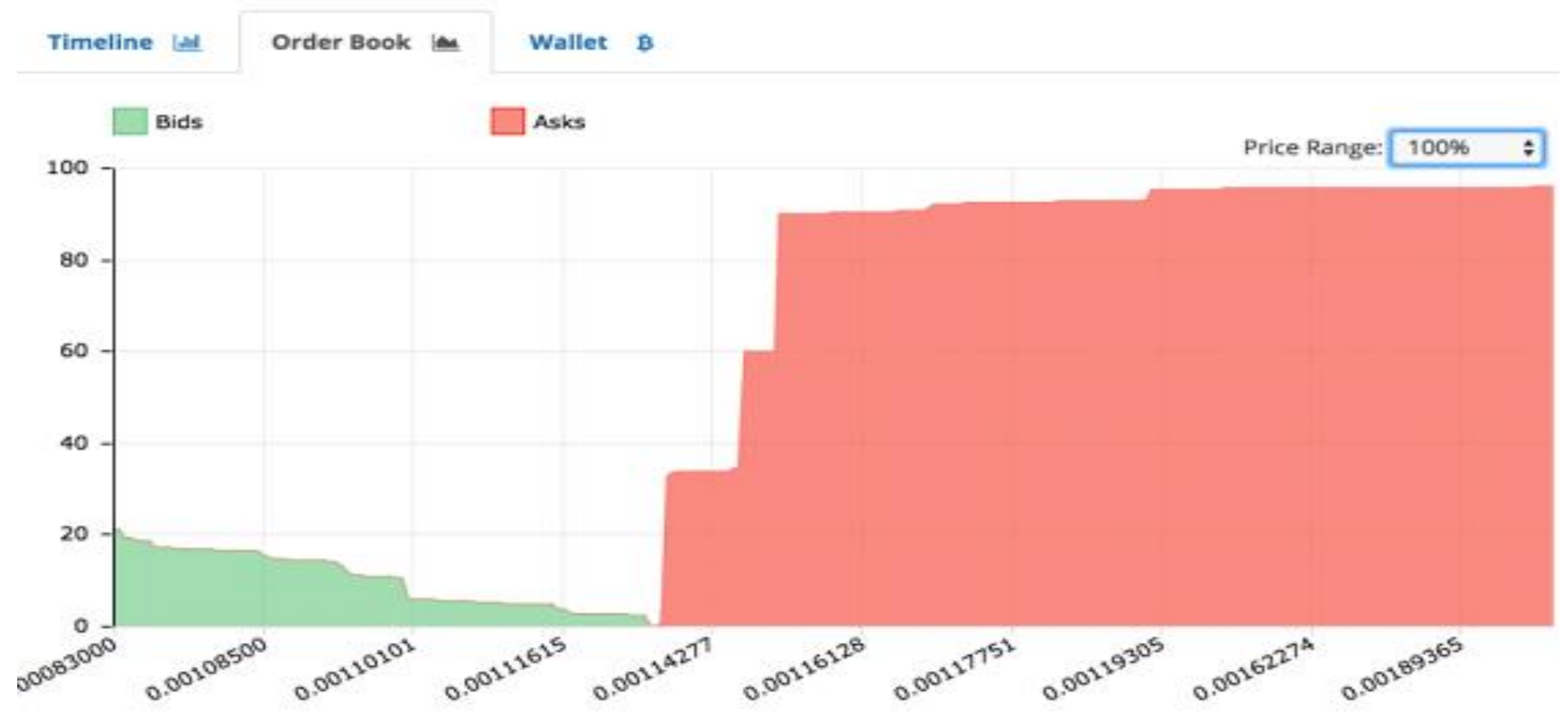

Fig. 1. Graph with a fake wall

Such "walls" do not always show the actual situation with cryptocurrency on the market. Sometimes large investors purposely throw a specific currency on the market in order to cause a sharp increase in prices. Then they wait until the traders sell their coins, and then they begin to actively buy coins at a lower price and again balance the volume and price of the currency in the market.

Not to be hooked, it should be remembered that the real "walls" do not collapse and do not appear in an instant, they usually tend to gradually rise and fall. Yet in this type of fraud, the "Pump and dump" scheme (fig. 2) is distinguished. This scheme is similar to the previous one. However, groups of unscrupulous investors are involved here. In private chats pump and dump groups discuss which currencies they are going to artificially raise (pump), and then sharply collapse (dump) in price. The similar schemes are as follows: a trader enters a closed group of pumps and dumps, in which a cash contribution is usually required. Then the leader of the group sets what currency needs to be pumped up and to what extent it needs to be dumped. Further, all participants buy this currency at a lower price.

Thus, the price of a coin begins to grow at an accelerated pace, and investors, in order to get money's worth, begin to actively buy it. Fraudsters sell the entire mass of coins, while other traders remain with the currency purchased at an artificially high price. Thus, we can conclude that a pump and dump group quickly makes money on a jump in prices.

One should beware of such groups and not join them because this is at least not legal and there is the possibility to be deceived. Investors should be beware of sharp changes in the dynamics of cryptocurrency prices. 


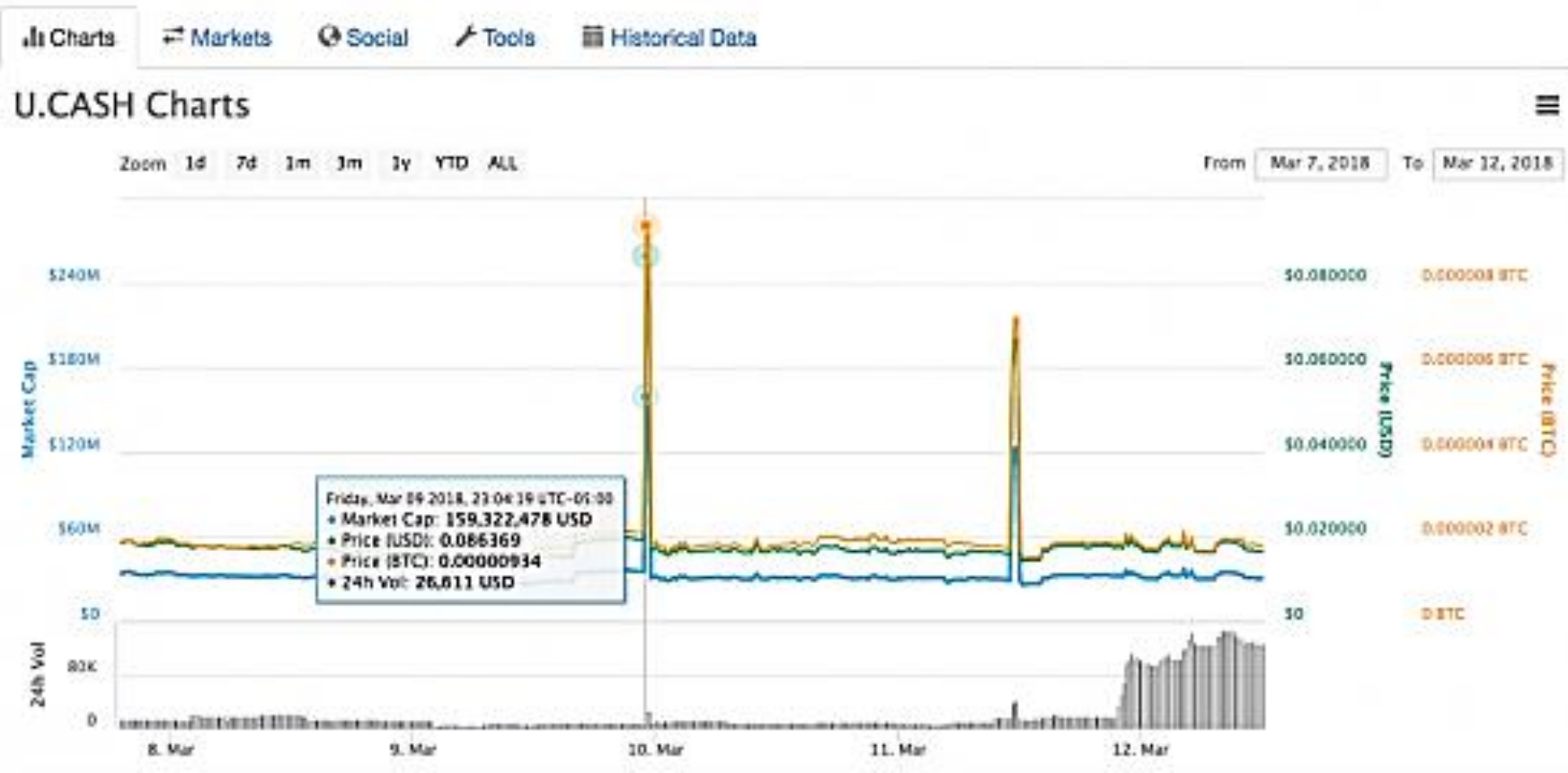

Fig. 2. Artificial pump and dump scheme

\section{CONCLUSION}

Thus, fiduciary money and cryptographic money have a common feature being a means of payment and exchange, and also play the role of an investment asset. At the same time, cryptocurrency is not an officially recognized and legal tender in many countries. The absence of a central emitter and a controlling administrator makes it an unreliable means of circulation and leads to a number of dangers for its owner. There are the following negative consequences: the risk of currency loss as a result of hacker attacks; the risk of depreciation due to the unlimited issue (mining) of electronic money; changing the legislative framework in the field of regulating virtual currencies up to a ban on the extraction and trade of cryptocurrency; participation in the illegal receipt of crypto money; the danger in transfers due to the inability to cancel a launched transaction; the use of digital money in criminal operations (tax evasion and various fraud schemes).

Obviously, the main threat to financial security from virtual money is the absence of a mechanism and the possibility of freezing funds from the outside, the absolute irreversibility of transactions and the impersonality of the parties in settlements. Cryptocurrency is gaining popularity in the modern world and not everyone approves this circumstance, since in the near future this will lead to a change of many sectors of life $[8,10]$.

In world practice, there is already experience in recognizing and developing a mechanism for regulating the circulation of cryptographic money. Bitcoins were officially recognized as currencies in Japan and Germany. In the US, virtual money is not fully recognized as a currency but regulates its conversion and is considered as property for tax purposes.
In Russia, cryptographic money is currently equated with "quasi-money" and is not officially recognized. Obviously, it is easier to ban cryptocurrency than to develop a mechanism for regulating its turnover. However, the ban most likely will not bring positive results, both for the economy and for society. Of course, the settlement of relations in the field of cryptocurrency exchange is a rather laborious process but it will prepare the country financial system, reduce potential risks and learn how to take advantage of the cryptocurrency turnover.

\section{References}

[1] Y.A.Salikov, I.V.Logunova, I.V. Kablashova, "Trendsinhuman resource managementin the digital economy", Proc. of the Voronezh State Univer. of Engineer. Technol., vol. 81, no. 2, pp. 393-399, 2019.

[2] I.A. Kiseleva, N.E. Simonovich, O.V. Pribytkova, "Economic and psychological aspects of estimation of risks of securitization of banking assets", Proc. of the Voronezh State Univer. of Engineer. Technol., vol. 81, no. 1, pp. 443-448, 2019.

[3] N.A. Serebryakova, I.V. Avdeev, "The content of structural transformations of the region's economy, adequate to the requirements of digitalization", Proc. of the Voronezh State Univer. of Engineer. Technol., vol. 80, no. 4, pp. 408-412, 2018.

[4] O.I. Vodyanenko, "Institutional dysfunctions of social economy and ways of their overcoming", Proc. of the Voronezh State Univer. of Engineer. Technol., vol. 80, no. 3, pp. 489-493, 2018.

[5] L.N. Shentseva et al., Fundamentals of managing economic security at the macro and micro levels, 2018.

[6] D.A. Logutenkov, I.S. Tsybalova, O. L. Lukasheva, "GDP as an indicator of the level of development of the financial sector of economy and country in general", pp. 89-93, March 2019, Topical issues of theory and practice of financial and economic activity [All-Russ. (National) Sci. and Pract. Conf., 332 p., 2019].

[7] N.E. Novikova, "Peculiarities of financial risks in the economic industries and the measures of their warnings", pp. 163-168, April 2018, Actual problems of economic activity and education in modern conditions, [13th Int. Sci. and Pract. Conf., 362 p., 2018]. 
[8] L. Singh, Cryptocurrencies: Is Bitcoin the Future for A cashless society, February 2018. Retrieved from: https://www.researchgate.net/ publication/322945027_Cryptocurrencies_Is_Bitcoin_the_Future_for_A _cashless_society

[9] J. Chiu, T. Koeppl, The Economics of Cryptocurrencies, April 2017. Retrieved from: https://www.chapman.edu/research/institutes-and- centers/economic-science-institute/_files/ifree-papers-andphotos/koeppel-april2017.pdf

[10] V.V. Smirnov, V.L. Semenov, A.N. Zakharova, E.N. Kadyshev and N.V. Bondarenko. "Self-Sufficient Urban Socio-Economic Space", Human. and Soc. Sci.: Novat., Probl., Prosp. (HSSNPP 2019), Advan. in Soc. Sci., Ed. and Human. Res., vol. 333. pp. 159-164, 2019. Retrieved from: https://doi.org/10.2991/hssnpp-19.2019.29 